\title{
Medical pluralism in a Dong Village, Southwestern China
}

\section{Chengpu $\mathrm{Yu}^{1}$}

Received: 14 December 2020 / Accepted: 24 January 2021 / Published online: 08 February 2021 (c) The Author(s). 2021

\begin{abstract}
Since Charles Leslie introduced the concept of "medical pluralism" in the early 1970s, there has been a steady stream of research in this domain. Based on a case study of a Dong (ethnic group) village in China, this paper attempts to present the complex operation of pluralistic healthcare and looks into the fundamental issues of pluralistic medical research. Results find that first, the future of pluralistic medical care system is in a flux. Second, plural medical care systems are in a state of symbiosis, which is dynamically compatible with local disease classifications. Third, the different elements of a pluralistic medical care system are in competition with each other, which depends on the maintenance of the daily doctor-patient relationship in the local society. This in-depth exploration of medical pluralism not only deepens the understanding of the topic itself, but also integrates the topic into local society and ordinary ethics.
\end{abstract}

Keywords Medical pluralism - Rural society - Disease classification - Doctorpatient relationship

\section{Abbreviations}

TCM: Traditional Chinese Medicine

\section{Introduction}

In the early 1970s, Charles Leslie, in his study of Asian healthcare systems, introduced the concept of pluralism or medical pluralism, which refers to a pattern of co-existence and competition among multiple healthcare systems in a specific region (Leslie 1973, 1976). Since then, although this concept has met with criticism,

Chengpu Yu

yuchengp@mail.sysu.edu.cn

1 The School of Sociology and Anthropology, Sun Yat-sen University, Guangzhou 510275, China 
there has been a growing interest in relevant research based on a pluralistic medicine framework. Broadly speaking, these studies focus on the following areas. First, researchers have tended to focus on a particular healthcare system within the context of pluralism. Examples include research on ritual healing conducted from the perspective of folk belief, discussion of the cultural logic of folk medicine from the perspective of kinship and social networks, and an anthropological exploration of biomedicine as a cultural system (Li 2009; Liu 2013; Latour and Woolgar 1986; Roberts 2012). Second, researchers have attempted to discover the reasons for the coexistence of pluralistic medicine, that is, to answer why these medical systems with very different theoretical origins, treatment modalities, and cultural meanings can coexist in the same society. The existing research results have generally demonstrated that the diversity of cultures and patient needs, and the complexity of social structures determine the diversity of medical systems (Zhang and Zheng 2015; $\mathrm{Xu}$ 2012). Third, researchers have tended to explore the interrelationships of diverse forms of medical care. Under the overall pattern of pluralistic healthcare, some scholars have found that various healthcare systems do not develop in a balanced manner but rather in a hierarchical way. Representing the triumph of globalization, the West, and the science, biomedicine has gained a hegemonic position in pluralistic medicine which is also driven by state power and modernity. However, biomedicine does not completely replace local traditional medicine, but rather competes and coexists with, and complements it (Lock and Nguyen 2010; Ember and Ember 2004). These studies focusing on different healthcare systems demonstrate the complexity of pluralistic medical care and its anthropological significances. Based on a case study of a Dong village in China, this paper attempts to present the complex dynamism of pluralistic medical care and looks into the fundamental issues of the topic.

\section{Methods}

The selection of a Dong village (pseudonym Shangzhai) as the field site does not mean that pluralistic medical care only exists here. This choice intends to demonstrate the dynamism of medical pluralism emerging from a more distinct background, which is the village, and to provide a living sample with typical significance for the topic. Apart from traditional medicine (Dong herbal medicine), there co-exists ritual therapy (usually conducted by witches), and biomedical medicine (known as Western medicine) in Shangzhai. The author conducted a fourmonth discontinuous field work in this village and has paid continuous effort to remain in contact with the villagers.

Shangzhai sits in the southwest of Tongdao Dong Autonomous County, Hunan Province, China. Located at the junction of three provinces-Hunan, Guangxi and Guizhou-Shangzhai lies at the foot of the 1336-m-high sacred mountain Sanshengpo. There were 675 households in the village with a total population of 2941 by $2018,97 \%$ of whom were of the Dong ethnic minority. In this village of nearly three thousand people, there are two designated medical institutions, namely, two village clinics, both mainly specializing in Western medicine and offering primary 
diagnosis and treatment of common diseases, and also shouldering public health duties such as disease prevention, maternal and child healthcare, and health education. In addition, there are two private clinics in the village, also specializing in Western medicine, which are run by two brothers. The private clinics do not have public health responsibilities and they do not accept health insurance. There are more than thirty herbalists and at least six specialize in witchcraft in the village. These herbalists are distributed in different family clans (房族), and are mainly in their sixties. The complex relationships between different health systems and within one single health system, as well as their relevance to the local community, are present in this village.

\section{Results and discussion}

\section{Prospects for the development of pluralistic healthcare systems}

The classification of multivariate medical systems varies in academic circles. The most common practice is to divide the medical system into two parts: Western biomedical science at one end, and other local medicine at the other end, which indicates the so-called traditional, alternative, complementary, and even "backward" medicine (Ember and Ember 2004,109-115). In the late 1970s and early 1980s, based on surveys in Taiwan and Boston, Arthur Kleinman divided healthcare systems into three distinct yet intersecting sections, namely, the popular section, the professional section, and the folk section (Kleinman 1980). Zhang Xun studied the medical behaviors of the Han People in Taiwan, especially those living in rural areas, and divided the medical affairs of the Han people into three parts, namely, the secular, the sacred, and the Western medical systems. Secular systems focus on long-term care, while sacred systems offer a supernatural explanation for patients' doubts, and western systems are superior in terms of efficiency and economy (Zhang 2000). The existing Dong herbal medicine, ritual therapy, and Western medicine in Shangzhai are more in line with Zhang Xun's division and correspond to the secular, sacred, and Western medical systems respectively in this study.

\section{Secular health system: transferring from dominance to a marginal role}

Shangzhai is located in a humid subtropical monsoon climate zone, where all four seasons are relatively mild, with few frosts in spring, low temperature in summer, less rainfall in autumn, and warmth in winter. With a forest coverage rate of about $70 \%$, the area has abundant water resources. Except for a few summer days when there is a slight shortage of water due to drought, it generally receives sufficient rainfall, which makes it suitable for the growth of rice, forest trees, water plants, and others. At an altitude of $1336 \mathrm{~m}$ above sea level, the Sanshengpo mountain is regarded as sacred hill by the locals, where a variety of rare trees, herbs and animals are to be found. Nature provides people with a rich source of livelihood and also with herbs for the prevention and treatment of diseases. 
Some herbalists have inherited medical skills from their ancestors, while some learned from their masters who are commonly their clansmen or relatives. Before apprentices formally pay homage to a master, they need to convey to the master their desire to learn the skill, either by themselves or by entrusting an intermediary. If the master is willing to accept the apprentice, the apprentice has to prepare wine, meat, rice, incense paper, and firecrackers, pay a visit to the master who is then saluted the master, and then worship the ancestors, after which the relationship between master and apprentice becomes official. As research on ethno medical heritage has shown (Cheng and Huang 2014), the master values most the apprentice's character and the qualities of integrity, honesty and helpfulness.

The study of herbal medicine begins with recognizing the herbs and learning their names, properties, and different harvesting techniques. For example, some herbs need to be uprooted, while for some others, only stems and leaves are required. Herbalists who know medicinal properties well can find whatever they need in any field. Some of the prescriptions are ancestral secrets that are only passed down within the clan, especially within the family, while most are common formulas familiar to most herbalists. On top of mastering plants' (sometimes including animals and minerals) medicinal properties, the apprentice has to learn how to diagnose patients' illnesses. Similar to Traditional Chinese Medicine (TCM), herbalists emphasize reliance on sight (for example, to look at facial features), smell (to smell breath), questions (to ask symptoms) and touch (to feel pulse) in treatment.

Elders report that in their youth they were usually treated by herbalists when sick.

Before the founding of the People's Republic of China, there were not so many people in the village, just a thousand or so, I don't know exactly the number. In the past, there were no hospitals, no health clinics, and we all had to see an herbalist when sick. Look at these people here, sitting in the Drum Tower (鼓楼)—most of their ancestors were herbalists. There are more than a dozen herbalists in each clan (房族) (there are six clans here). Those famous herbalists also go to other places, some go to neighbor provinces of Guizhou and Guangxi to treat patients. There is certainly no problem in herbalists treating minor ailments and pains, but some serious illnesses cannot be treated well through this method.

-Mr. Shi (Shangzhai villager, eighty years old)

Herbal medicine was undoubtedly the most important source of medical care for locals before Western medicine was introduced to the village. People sometimes turn to shamans, but many herbalists are themselves skilled in witchcraft as mentioned above, so it's just about different ways of treating patients with the same drug. For quite a long period after the founding of New China, the dominant medical treatment in the village remained herbal medicine. During the period of the “barefoot doctors"(赤脚医生) in the late 1960s to the late 1970s, some of the "barefoot doctors" were also herbalists.

Most often the barefoot doctors treat people with herbs. They write prescriptions, then the hygienists collect [the herbs] and boil them. In times of 
epidemics, herbs are distributed to community members working in the fields. Due to the low cost [of this healthcare], each villager paid fifty cents (RMB) per year and a registration fee of five cents per visit to the doctor to cover all the medical expenses of a year at the health center (this was the rural cooperative medical system in the early days of New China).

-Mr. Yang (barefoot doctor)

After the 1980s, herbal medicine gradually declined and became marginalized. One obvious sign is that herbalists now find that there is no one to succeed them, and many old herbalists have not passed on their lifelong skills to their children or any others; young people are reluctant to study herbalism, preferring instead to go out to work for a living. Over the years, some rare herbs have become more and more difficult to obtain due to the massive collecting by herb-receiving stations in the village and town. Sometimes an herbalist has to make several trips up the mountain in order to prepare enough of a medicine, and they often reap only a small reward. In times of economic deprivation, they would treat people with a bundle of herbs for only one yuan. Sometimes, patients would pay for the service later through payment in kind. This kind of exchange not only earned the herbalists respect, but also a considerable income. Nowadays, prices and manpower costs are generally rising, the payment of a dozen or so yuan for herbal medicine is too low compared to other labor income, which naturally discourages herbalists' motivation. According to preliminary statistics, there are more than thirty herbalists in the village, but fewer than ten are currently practicing.

I'm too tired to treat anyone this year. The patients pay around 10 Yuan RMB at a time, and some don't pay; I can't justify the time I spend. Now I work in construction, building houses, making 120 yuan a day, and some are getting two hundred yuan for those with skills. I sometimes go looking for herbs, and it takes me a few days to get them ready, after which I make ten yuan. What's the point of doing that?

—An old herbalist

The marginalization of herbal medicine does not mean its complete withdrawal from the village. On the one hand, people still believe that herbal medicine can cure their diseases. For some long-standing illnesses, patients and their families still devote their hopes in herbalists, hoping that they can give them the silver lining of cure. On the other hand, most of the ordinary villagers were familiar with the medicinal properties of plants during their continual dealings with herbalists, and they practiced basic herbal knowledge in their daily healthcare. Traces of daily healthcare can be seen everywhere in Shangzhai village. It's a common scene that different herbs are drying out on the first floor or the top floor of some houses. Villagers would serve guests with herbal tea with a faint medicinal flavor in summer. According to the villagers, they would pull some grass roots from the fields and boil them in water, then serve it to the whole family in order to protect their families from the risk of 
heatstroke in the hot summer. Older men like to smoke raw tobacco, using dried mugwort leaves to start their fire. They roll large mugwort leaves into moxa, light them on fire, and allow the smoke to enter painful parts of the body (烧尒); this is said to treat rheumatoid arthritis, bruises, chronic pain, and other physical ailments, and habitual use has allowed it to become part of people's daily healthcare routine. The once dominant role of herbal medicine is gone, yet its success as a secular medical system is that herbal knowledge is widely available as the main source of knowledge for daily healthcare.

\section{The sacred medical system: shifting from a repressive to an active state}

Yang Lian, born in 1937, was a short-statured man who worked as a teacher in Guizhou province when he was young, then came to this village to work as a farmer after liberation. After the 1990s, he went to the nearby towns and villages to set up stalls for reading and telling fortunes. He was often teased by the villagers as the "superstitious leader" (迷信头子), but he didn't mind and took the trouble to tell them about his "glamorous" experiences.

Sometimes it's good to believe in superstitions. For those diseases that can't be cured by pills and injections, superstition may help. For example, when I was in Boyang town, the wife of a government agency secretary was sick and asked for my help. Up until that point, they had spent more than ten thousand yuan in hospital fees, but his wife was not cured. Later, they came to me for a fortune telling and I found out that she had violated the "Short Life Pass"(短 命关) and “Hell Pass"(阎王关). I helped her turn a bad fortune into an auspicious one. After some time, she was cured. Later he [the secretary] wanted to thank me and invite me to dinner, but I didn't go.

- Yang Lian

While most of the shamans are elderly, Yang Yi, the most active shaman in the village at the moment, is actually a fifty-two-year-old lusheng (芦笙, a wind instrument) master. Although Yang Yi is a master lusheng maker, he is not known for this skill, but for the ritual healing he has engaged in during the last 3 years. It is said that he met the Great God and was given the special ability to predict misfortune and avert danger. His room is always lit with incense and burning paper, making the room very smoky. Yang Yi was always sitting in this smoke, surrounded by many people who came from afar for help. Most of these people are villagers from the neighboring provinces of Guangxi and Guizhou, or from nearby villages, who sometimes come at three or four in the morning to line up.

I don't have time to make lusheng now. Compared to the low fees people pay to grass [herbal] healers, the fees they pay to shamans are twenty, fifty, one hundred, or several hundred yuan. Roughly speaking, I earn almost 300 to 500 Yuan or more per day, so naturally I don't have to rely on lusheng-making to make a living."

- Yang Yi 
Yang Yi has business acumen as well as commonweal ideas. While earning a high income, he hired people to start a tea factory in the village. He donated two hundred thousand yuan as an individual to road construction. However, being rich and public-spirited did not offset the villagers' negative opinion of him. Villagers always thought him to be a fraud who never had any special skills.

He just got lucky and made a lot of money by scamming outsiders. We (the locals) don't believe in him. Good luck doesn't last forever, sooner or later he will be in trouble. Look at his son, who is intellectually challenged. That's a form of retribution.

A villager

Yang $\mathrm{Yi}$ is probably aware of the villagers' bad impression of him, and when asked if the villagers trust him, he is slightly disdainful and a bit arrogant, saying, "They usually don't believe it [the efficacy of what he does], but whenever there's a problem, they believe it. Every family here has come to me for a ritual."

Why is Yang Yi's witchcraft profession met with resentment from villagers and yet the villagers turn to him in times of trouble? The contradiction shows people's ambiguous attitude towards witchcraft, that is, their half-belief. When the family is at peace and all members are well, they seldom deal with witches; when misfortune strikes and there is no other solution, they will not give up if witchcraft offers a glimmer of hope. When there is still hope, people always do something and do not easily reject other possible life-saving measures. However, people's negative feelings about witchcraft are evident when some are paid handsomely for practicing sacred healing, a superstitious activity that was suppressed in the early days of New China. Compared to the daily hard-earned money of ordinary villagers, this income is almost ill-gotten. Like herbalists in the village, shamans also learn from a master. Yang Yi's so-called encounter with a Great God and being granted special abilities is seen as a false claim and not trusted by people. This causes him to seemingly be in the limelight and on the move, but he also faces an awkward moral dilemma.

\section{The Western health system: stepping from a complementary role to a strong position}

Western medicine entering into China is no doubt a part of China's modernization, and its penetration into Chinese rural society is closely related to state power and the force of modernity. In 1965, Chairman Mao Zedong issued a call to focus medical and healthcare work on rural areas, which opened the door for the proliferation of Western medicine in the Chinese countryside. In the late 1960s, Shangzhai had its own health clinic in which the medical staff were registered as permanent rural residents and were "half peasants and half doctors," in other words, they were the so-called barefoot doctors (赤脚医生). As has mentioned above, the barefoot doctors were from an herbalist background, which was still dominant at that time.

Although I had learned about Western medicine and Western drugs, there were very few Western drugs then, and even fewer were distributed to the village 
health center. There was only one injection syringe in the entire center, which had to be sterilized by boiling in water before injection. At that time, the main focus was on preventing disease and relieving pain, rather than curing it, as there was no condition to cure it.

A barefoot doctor

Although barefoot doctors already had access to Western medicines for fever, cold, and diarrhea, as well as painkillers and penicillin, when compared to herbal medicines, they were both scarce and costly, and served only as supplements. In the early 1980s, while the reform of the household responsibility system was being promoted, the former barefoot doctors began to transform themselves into village doctors. A distinctive feature of village doctors, as opposed to the semi-medical and semi-agricultural practice of barefoot doctors, is that they have gradually moved away from agricultural production and are carrying out specialized medical work. In contrast to grassroots doctors, rural doctors generally undergo specialized training in Western medicine and obtain a certificate of qualification issued by the health department before they can practice medicine.

Unlike herbalists and shamans who perform impromptu treatments at home, Western healers have a specific space and a prominent display of their credentials and the name of their medical facility. In Western medicine clinics, some over-thecounter medicines at marked prices are kept in separate cabinets, and there is also space in cubicles for injections and clinical observation. These spatial arrangements underscore the normality and legitimacy of Western medicine clinics in comparison to other healthcare systems. However, compared with urban Western hospitals, rural Western medical clinics not only lack a clear division in terms of spatial layout, but also show a localized aspect in their daily practice. For example, first, they usually communicate with patients and their families in the local language. Second, they do not wear white coats during consultations. Third, when other families have celebrations, doctors will come to help as members of the village. Such behaviors indicate that Western medical clinics in the countryside are not only different from other medical systems through their spatial and symbolic settings, but are also closer to ordinary villagers through the daily life of Western-medicine doctors.

It was observed that the large number of young adults working out of the countryside, while leading to the decline of herbal medicine, posed little threat to Western medical clinics and even contributed to some extent to the latter's outpatient visits and especially the use of antibiotics. Young adults who are migrant workers are already at their healthiest stage of life, therefore they rarely get sick, and an occasional minor illness can be self-healed without medication. However, the two groups most prone to fall ill, the elderly and children, stay in the village. It was observed that in the village health clinic, infusions of antibiotics were common among the elderly and children, and even some one-month- old infants were given antibiotic injections with needles in their foreheads.

The misuse of antibiotics has been discussed in terms of physician power, market interests, and villagers' medication habits (Jing and Huang 2016). This paper argues that the migration of young people from villages, and the ethical pressures this migration creates become a force that cannot be ignored in promoting the use 
of antibiotics among the elderly and children. For young adults, filial piety is a traditional ethical requirement of their behavior toward their parents and parents inlaw. For their children, they also need to feed them with great effort. However, it is clear that their duty of filial piety and child-rearing are not being fulfilled due to their absence in the village. Filial piety becomes a matter of one elderly person taking care of another, and the burden of child-rearing is being placed on the elderly. If a child is sick and the parents are not around, the elder's biggest wish is that the child can get better quickly, saving the absent parents from worries and themselves from troubles. When the old people themselves are sick, one concern is that their grandchildren would be unattended, and the other is that their children who work far away from home would be worried. If the elders are not urged to see the doctor, the neighbors would blame the children for being ungrateful. Under this dual ethical pressure, seeking treatment at the nearest clinic became the preferred means of treatment. The efficiency, speed, and convenience of Western medicine compared to herbal medicine fits the urgent psychological and ethical need of people to eliminate pain. Changes in the rural social structure have further promoted the dominance of Western medicine in rural areas.

\section{Complementary Symbiosis within pluralistic healthcare systems}

The ethnographic survey found that different groups of people adopt different healthcare systems universally, and that the difference lies in the varied circumstances under which people would choose different healthcare system (Yu 2016). The type of disease, patient's condition, folk beliefs, treatment effects, accessibility of transport, medical costs, and verbal communication all influence people's choice of a specific medical system (Liu 2006; Zhang 2011). The type of healthcare system chosen by the villagers of Shangzhai was also related to the variables above, yet the classification of diseases could be the basis for people's choice of healthcare systems.

Villagers and healers have constructed two main classifications of diseases in their long-term interaction, that is, somatic disease (身病) and destined disease (命 病). Herbalists (and later Western physicians) provided primarily medicinal treatments and dealt with somatic diseases, while shamans dealt with destined diseases through ritual healing. There is an eighty-year-old herbalist in the village who not only specializes in witchcraft, but also studied Western medicine during his barefoot doctor career. According to him, there is no apparent conflict between the three medical systems integrating into one.

Dong doctors pay attention to the six causes of disease, namely heart, liver, spleen, stomach, kidney, and destiny in treatment. The first five will lead to somatic diseases while the last one is doomed to [generate] destined diseases. Destined diseases are mainly based on the three stages, namely the head, waist and stomach. If a person has passed through the three stages, he or she will be in danger. If one is suffering from destined disease, medication won't have any effect."

An herbalist (eighty years old) 
Somatic diseases are easier to identify, and include common illnesses (e.g., colds, diarrhea, etc.), work injuries (e.g., back strain, fractures, etc.), and chronic illnesses (e.g., hypertension, arthritis, etc.). Minor somatic problems can be managed within the family. For more serious illnesses that affect their lives and work, people have to seek treatment from herbalists or go to health clinics and take medication, intramuscular injections, or intravenous injections. After all this, if they still do not get better, it is certainly beyond the reach of the local healthcare system and they have to go to higher-level health clinics and hospitals, or even resort to ritualistic treatment, treating the disease as a destined one.

Experienced villagers are able to determine whether a physical ailment is a somatic or destined disease. For example, if a healthy person who can eat two bowls of rice in the morning (villagers often take the ability to eat as a sign of good health), but begins sweating profusely, and is pale and exhausted when he comes back in the evening, then he may have "met a ghost" and needs to be exorcised according to the villagers' diagnosis. For another example, children's night terrors (夜惊) are often thought to be a result of a child's lack of yangqi (阳气, positive life-energy) and susceptibility to evil spirits, which requires a shaman's treatment or the wearing of an amulet to ward off evil spirits.

The Dong people, like many Han people, believe that after death, people either become ghosts or reincarnate as humans. There are good and bad ghosts. Those who die accidentally, such as those who died prematurely, were drowned, hanged, killed, or died in childbirth, or who died unmarried, as well as those who were generally buried in mass graves instead of ancestral graves, and who cannot be worshipped by their descendants will become wandering ghosts who haunt the world and give people no peace. Generally speaking, ancestors do not harm their offspring, but they may make trouble. To quiet them down, the living would turn to witchcraft and burn some belongings of the dead as an offering. Villagers also believe that people have three souls. The body becomes unhealthy when the souls are lost, hence it is necessary to find a shaman to locate where the soul is and perform the ritual of calling it back.

A lady once turned to the shaman Yang Yong to cure a stomachache. Her eldest daughter-in-law, who was working in Fujian province, had been suffering from stomach pains but could not be diagnosed by the doctors, so she asked Yang Yong to find out what was she sick with. Due to the loss of his eyesight and his advanced age, Yang Yong had much difficulty moving around, so his wife had prepared a table and incense paper for the sorcery ritual in advance.

The lady offered a small packet of rice, a salted fish, an egg, sixteen yuan, two kilograms of cured meat, two kilograms of rice wine, and the patient's personal clothing. Yang Yong's wife poured wine into three bowls and placed them in front of the table, while water was poured into another bowl and placed behind the table. In the middle of the table were bowls of fish, meat, rice, eggs and money brought in by the help-seeker. His wife then lighted three incense sticks and placed them in a small incense burner on the table and prepared several stacks of yellow sacrificial papers to be used. When everything was ready, the shaman started his magic. He conducted the rituals of divination, invoking the gods, passing through the Yin world (talking directly to the spirits), and spraying water (expelling evil spirits with 
the help of gods), and then returned the clothes from the spell to the lady, so that she could take them back to her daughter-in-law to don, and thus the ritual treatment was complete.

Ritual healings are usually performed by shamans, while herbalists also perform small rituals such as “inviting the master”(请师傅) when treating serious illnesses. For example, when a Dong osteopath is faced with a patient who has suffered a severe fracture, he will ask the family to prepare meat, wine, eggs, rice, incense and ritual paper. Preparing five bowls of wine and a bowl of water, the osteopath begins to invite his masters and ancestors, asking for their help to heal the patient, and then recites incantations, sprays water, and exorcises demons to keep evil forces from interfering with the healing process. Only after these rituals can the osteopath touch the patient to set the bones and apply the medicine. Later, when the patient has recovered, there is an "illness root breaking" (断根) ceremony to ensure that the pain does not recur.

There is no doubt that the rituals above are exceptionally rich in detail, fully demonstrating the Dong people's view of the world and of ghosts. People will also turn to shamans for general somatic diseases (such as stomach aches) when no other solution is available. Some herbalists also use rituals, in addition to medicine, to treat serious health conditions such as broken bones. Western doctors in the medical clinic, though trained in modern medicine, prescribe herbal remedies at the request of the patient, and even recommend that the patient go to a shaman for ritual treatment when there is no hope of cure with medicine.

Cases have shown that there are no clear boundaries for destined diseases, and that every somatic disease can become a destined disease when it is difficult to cure. Those diseases for which neither herbalist nor Western doctors can offer remedy, patients might come to believe they have broken the rules of life. In such cases, they will find a shaman in the village or in the neighboring area to perform rituals for confirming whom they have offended. The shaman performs the sacrificial rituals to solve the problem, either by sending away ghosts, exorcising evil spirits, praying for blessings, or invoking spirits.

Most villagers are half-believers and half-disbelievers in ritual treatment for destined diseases, believing that treatment cannot completely rely upon ritual therapy, but that it needs to be supplemented by other means of medicine. Ritual healing and medication are not mutually exclusive. They are often two-pronged and intertwined in the treatment of people's ailments. Further, each healthcare system may deal with a variety of diseases, and conversely, each disease may have a variety of treatments. This indicates that the relationship between disease classification and healthcare systems is not a definite one-to-one counterpart, but rather demonstrates a dynamic genealogical pattern, under which all healthcare systems coexist in a symbiotic status.

\section{Competition within a single pluralistic healthcare system}

Western medicine is bound to have more of a competitive advantage both in terms of legitimacy and resources in the current medical environment. Due to the 
disparity in status, Western-medicine doctors don't even bother to compete with herbalists and shamans. If there is competition within a pluralistic healthcare system, it is not primarily between healthcare systems, whose complementary and symbiotic relationships have minimized competition, but rather between professionals who share the strengths and weaknesses of the same healthcare system to which they belong and who generally serve the same community. Naturally, skill and cost are the two factors that matter most in terms of who will win more patients. However, unlike urban hospitals, which classify doctors into different levels of titles (which are often used by patients as a basis for judging the doctor's skills), rural doctors rarely have such titles, and they only diagnose and treat common illnesses at a rudimentary level, making it difficult to distinguish their medical skills. In the rural society, medical skills and costs do not work alone, but are always linked to the interpersonal logic of the rural society.

\section{Interpersonal trust is an internal competitive factor}

There are four Western medical health clinics in Shangzhai, and during the fieldwork an obvious phenomenon was revealed: the Yang family's health clinic receives many patients every day, such that sometimes there is not enough space in the health clinic and, therefore, patients have to take an intravenous drip in the open space outside the clinic. However, the Shi family's health clinic only occasionally has some patients. The two brothers of the Huang family established their private clinic more than 10 years ago and have a relatively stable patient base.

The Yang family is now almost the richest in the village, having bought a flat in the county town, a car, and the most upscale three-storied brick house in the village.

-A villager

These external symbols became the standard by which people judged wealth and poverty. Unlike the villagers' bad-mouthing of shamans, above, the villagers had no animosity towards the Yang family. Respondents always gave Doctor Yang the highest praise, trusting not only his skills, especially in giving injections to children, but also his personality. For example, he has a good attitude and speaks in a soft voice. He always listens patiently to patients' complaints, no matter how old or how young they are. It is because of his reputation that the elderly and children in the nearby villages who are sick would rather walk a few miles more to see Doctor Yang.

Villagers are much more casual in their assessment of herbalists, seeming to value their character more, and sometimes, instead, to lower their expectations and trust in their medical skills because of the herbalists' character. There was an herbalist in the village who had such a bad reputation that a well-meaning villager even warned the researcher not to associate with him so as not to be deceived. The forty-nine-year-old herbalist, who lives in a modest house with a ten-year-old adopted daughter, had had a tragic experience: 
When I was young and working in Guangdong province, my right arm was crushed by a machine and had to be amputated, and then my wife left me. I was smart and could learn many things right away. I learned how to weave all kinds of baskets as a child, and later I learned osteopathy, treating stomach problems and rheumatism, from my sister-in-law's father. I also knew a little about feng shui (风水). But I never gave medical treatment in the village, I felt that the village people were too snobbish and they looked down on me because they thought I was too poor. I prefer to go to neighboring villages in Guangxi and Guizhou provinces to sell baskets and treat people there.

-An herbalist

A few villagers were told about the herbalist's situation by the researcher, but the villagers were dismissive of him and thought him a bad person, suggesting they would have less dealings with him in the future. The villagers judged his amputation differently, believing that it was not caused by his working in Guangdong province, but by local villagers who discovered him stealing cattle in Guizhou province and beat him up. With a notorious reputation for stealing, people's trust in him was minimized and they even hated him.

Yang Quan, sixty-one-years-old, had worked briefly as a barefoot doctor in Shangzhai in his youth. He then moved to Guangxi Province where he contracted with a tea garden and made a living by picking tea and occasionally treating illnesses for the locals. He was 15 years old when he married a wife in her twenties. The young wife had given birth to three children but had died in childbirth during the birth of their last child. After leaving the hospital, Yang returned to Shangzhai village and opened a barber shop, which soon closed down because no one was interested in it. He picked tea leaves to make a living, which in the area was mainly women's work. On every second, fifth, and eighth day of the lunar month, he would go to the local market to sell herbs and a few Chinese medicines. His signboard was filled with names of all kinds of diseases, from stomach ailments, to rheumatism, all kinds of cancers, and gynecological ailments, and stated the potential to cure all kinds of diseases. One day, he spread the herbs in the open field in front of the village council, but after nearly $2 \mathrm{~h}$, not a single person bought his medicine.

In rural villages, a man would become a candidate to be a life-long bachelor if he has not married by the age of thirty. Behind the idea of bachelorhood there is a set of related words, for example laziness, poverty, or their own faults. Yang Quan didn't get married until he was fifty, and had already carried the stigma of being a bachelor for 20 years. The age difference between him and his wife was so great that the villagers offered veiled criticism about it. Whenever they talk about him, the villagers think that he must have played a trick on the wife, saying that he was "an old cow eating young grass" unworthy of his young wife. His wife's death in childbirth was seen as a death with ill omen, which in turn reinforced local resentment against him. Other herbalists were also extremely dismissive of his going to the market to sell herbs, arguing that herbalists were not there to make money, but to help others and should not attempt to make a living out of it. 
He's a charlatan! If his medicine really worked that well, why would he go around peddling herbs? He himself would not be haunted by disease if his medicine really worked. People of our village would not be fooled, only those from other villages would be.

-Neighbor of Yang Quan

This case demonstrates the complex association of medical skill, reputation, morality, and trust in a good doctor-patient relationship in a village. A doctor is evaluated not only on his skill, but also on his character, so whether he or she is an herbalist, a Western-style doctor, or even a shaman, they all try to avoid doing things that tarnish their reputation or violate the rules. Otherwise they will bear a bad name and naturally be condemned to an inferior position in competition with their peers.

In Anthony Giddens' discussion of trust, he places more emphasis on systemic trust, although he distinguishes between interpersonal trust and systemic trust (Giddens 1990). Specifically, in terms of trust between doctor and patient, in the wave of modernity, the patient trusts not in any particular doctor, but in the doctor as a profession or as an abstract system of experts. This research found that trust between doctors and patients in villages is first and foremost based more on interpersonal trust, which relies on the doctor's moral attitude and behavior in the village and the related public opinion. It is based on the details and events of daily life and is not absolutely abstract, but accessible and descriptive. Establishing a good relationship of trust, which in turn develops into a good doctor-patient relationship, is what earns a reputation and a competitive advantage within the same healthcare system.

\section{Renqing (人情, social relationship of gifting) Is Another Internal Competitive Factor}

When people choose a doctor within the same healthcare system, apart from the doctor's skill and character, cost is another important factor that they consider. In Western medical clinics, some of the common drugs available over the counter are marked at a price that is not negotiable, while others (mainly for intramuscular and intravenous use) are priced entirely by the doctor. Sometimes, when the cost exceeds the patient's ability to pay, instead of asking for a reduction in the price of the drug, the patient begs the doctor to reduce the prescribing of some non-critical drugs. Doctors also have to take into account the patient's ability to pay the bill. Patients who can't afford to pay for more expensive prescriptions will be granted credit though they could default on the payment, eventually ending up on the doctor's own bill. On the other hand, fees that are too high could give doctors a bad reputation for overcharging, which makes it hard for them to earn a good name.

Some of the common medicines in the four health clinics are, like tobacco and alcohol, tracked by the villagers who know exactly which are more expensive and which are cheaper. Sometimes, even if it's just a few cents cheaper, people pay extremely close attention because it shows the character difference between the doctors. As previously mentioned, in the village, most families are left with only the 
elderly and children. Many elderly people are illiterate and have no idea of the price of the medicines. Sometimes before the young people go out, they would ask the village doctor to keep a record of the bill, and when they return home for the Chinese New Year, they will settle the bill by cash or use their health insurance card. In this village, where everyone is either of the same family or more or less related to each other, the village doctors cannot refuse these requests from the villagers. In fact, these doctors are willing to bring in more patients as a result of their good deeds. All they need to do is record the details of the date, the illness, the treatment and the cost, awaiting the young man in the family to settle the bill at the end of the year.

The survey found that there have been no recorded disputes arising from the village doctor's wrong bookkeeping and over-swiping of health insurance cards. Doctors confessed that they would not take any moral hazard for it, but they would be upset about having too much credit for too long, with some debts having been in default for 10 years, a situation that certainly increased the burden of their payments in advance. Hence when these patients who have long defaulted on their medical bills come back for help, doctors are forced to prescribe cheaper drugs just to ease pain temporarily.

As mentioned above, there are four health clinics in Shangzhai that focus on Western medicine, two of which are the designated medical institution where villagers can use their health insurance cards to make purchases, while another two private clinics run by two brothers are not part of the new rural cooperative medical system. In this comparison, the two private clinics don't have much of an advantage, but they have both survived in the village for more than a decade, and each has a stable clientele.

A doctor was interviewed and asked to comment on the experience of running a private clinic.

We rely heavily on quality service here to keep the clinic running. Whenever a patient needs something, a call comes in and we'll be there. This is not enough. The people who come to me are relatively regular, and I'll be thinking about the cost as well. For example, that patient who just left, he fell when he was going up the hill with a wood chopper and hurt his foot. He now has to come in every day for a drip to reduce inflammation. He has been here eight times; according to the normal charges, that's over six hundred yuan-more than seventy yuan per visit. We are cousins and I only charged him three hundred yuan.

-A doctor in the private clinic

The investigator later interviewed this patient. When it came to choosing a doctor, he indicated that he would prefer this private clinic because they were related and charged less. For the patients, choosing a relative (or other relation) to see a doctor is a kind of taking care of the clinic business. The doctor is not insensitive and will show some kind of return in terms of discounts or other services. In contrast, herbalists don't treat patients as the main source of their livelihood, but are more helpful and humane. Some herbalists told the researcher that their original 
intention in learning herbalism was to deal with illnesses in their families, and over time, they could not refuse the neighbors, relatives and friends who requested help when they were sick. Unlike the marked-up prices of Western medicine, the costs incurred by herbalists treating people are entirely the patient's own decision. "Giving more is never too much, and giving less is never too little" is how herbalists often talk about the costs.

The villagers used to pay one yuan for a pair of herbs and three to six yuan for each visit, and now they only need to pay a little more than ten yuan for a single visit. Occasionally, patients from good families will pay hundreds of yuan when their illnesses are cured. Of course, there are also some relatives and neighbors who come to take medicine and don't pay any money. These relatives and neighbors, of course, are familiar with rural dealings and will repay this free medical treatment through other means, such as helping out or sending some of their own rice wine, as a return gift. An orthopedist in the village told the researcher that his most recent treatment for a fracture was to treat a patient from a neighboring village who came to visit him because of his good reputation. Due to the inconvenience of his injured legs and feet, the patient stayed at his home for a week, and returned home only after his injuries had improved. During this time, the orthopedist did not charge the patient any money, and food and lodging were also free. After the patient went home, a few days later, the patient, together with his family, came back with wine, pork, eggs, rice, handwoven cloth, and other ritual goods, requested that the orthopedist do a "disease root breaking ceremony" and expressed their gratitude to the orthopedist.

In local societies, the most central mechanism that governs relationships between people and families is renqing (Yan 2000). In urban institutionalized medicine, doctors are often confronted with patients who are strangers and with whom they seldom have any personal contact, whereas the doctors in Shangzhai are themselves part of the local community and deal with patients who are essentially from the same village or household; it is inevitable that they are related to each other. This means that in local societies, in addition to the general therapeutic relationship between doctor and patient, there is a need to deal with the relationships between people, families, and clans within the village, and renqing become the glue of this relationship. Bringing the human touch into medicine makes the doctor-patient relationship in the village such that it is never a presentation of cold rules, nor is it entirely dominated by money and fees, but always with some renqing touch. This renqing touch makes different practitioners each have their own patient resources, forming a relatively stable doctor-patient relationship structure in the village.

\section{Conclusions}

Based on an investigation of a Dong village, this paper presents a more stereoscopic view of the complex dynamism of pluralistic medical care. First, the outlook for different healthcare systems is in constant flux as times change. The secular medical system (mainly herbal medicine) has moved from the dominant to a peripheral position, both in relation to the entry of Western medicine and the transformation of village livelihoods; 
however it has not completely withdrawn from the village and has become an important source of knowledge for people's daily healthcare. The sacred healthcare system (largely presided over by witches) is ostensibly vibrant after a history of repression, but actually faces some moral dilemmas. The Western healthcare system (i.e., Western medicine) has gone from a complementary role in the past to a powerful position today in relation to the country's modernization process and the strength of Western medicine itself, which has adapted to the social structure of the village and the villagers' quest for medical efficiency.

Secondly, at present, each medical system is in a state of complementary symbiosis which is dynamically compatible with the local classification of diseases. While within the homogeneous system of pluralistic medical care, there is a state of competition that relies on the maintenance of the daily doctor-patient relationship in the local community. In Shangzhai village, diseases are divided into somatic and destined diseases. However, it is not a one-to-one correspondence from somatic disease to destined disease and from medication to ritual treatment, but rather presents in form of a continuum. Any somatic disease that is difficult or persistent to treat may be considered a destined disease, the cure of which must resort to rituals. In the process of ritual healing, shamans also assist with herbal and Western medicine. The blurring and continuity of the boundaries between somatic diseases and destined diseases determine the basic state of complementary symbiosis of pluralistic medical treatments. Within the same medical system, different medical practitioners are mainly in a state of competition, and the bargaining chips of their competition appear superficially to be medical skills and costs, but at a deeper level, they are closely related to the logic of the social operation of the local community.

This study suggests that ordinary ethics may be an important entry point for research in pluralistic medical theory (Das 2012; Lambek 2010). Ordinary ethics is not concerned with special areas such as religious good and evil, human rights, professional ethics, bioethics, nor with pre-defined rules, nor with abstract topics discussed by philosophers, but rather with people's everyday behavior. Introducing ordinary ethics into the study of pluralistic medicine reveals that, on the one hand, pluralistic medicine deals with the commonplace everyday matters of life, old age, sickness, and death. People's classifications of diseases and choices of healthcare systems are not derived from rigid criteria, but are based on the pragmatic, random, and dynamic features of everyday life. On the other hand, pluralistic medical care is not only subject to the general medical ethics (such as informed consent, do no harm, etc.), but also within the ethical scope of people's daily interactions and daily life, which regulates the relationship between doctors and patients and influences people's choice of medical treatment and the judgment of it, thus making the local doctor-patient relationship not a form or result of institutionalized regulations, but a concrete manifestation of daily interactions in medical treatment. While presenting the operational state of pluralistic healthcare, it can be seen that pluralistic healthcare is not an isolated matter in local societies, but is closely related to disease types, belief systems, state power, livelihood transformations, and even to the ethical principles of native societies. The actual operation of pluralistic healthcare is a reflection of the contemporary local society, which provides an indispensable perspective for the theoretical research of pluralistic medical treatment. 
Acknowledgements Not applicable.

Author's contributions Chengpu Yu conducts the whole research and writing. The author read and approved the final manuscript.

Funding Not applicable.

Availability of data and materials available from the author upon request.

\section{Declarations}

Ethics approval and consent to participate Before taking the participants' interview, the author obtained their oral consent. They understood the purpose and significance of the survey. They can also leave the interview at any time. All recordings were made with their consent.

Consent for publication Not applicable.

Competing interests We have no any competing interests.

Open Access This article is licensed under a Creative Commons Attribution 4.0 International License, which permits use, sharing, adaptation, distribution and reproduction in any medium or format, as long as you give appropriate credit to the original author(s) and the source, provide a link to the Creative Commons licence, and indicate if changes were made. The images or other third party material in this article are included in the article's Creative Commons licence, unless indicated otherwise in a credit line to the material. If material is not included in the article's Creative Commons licence and your intended use is not permitted by statutory regulation or exceeds the permitted use, you will need to obtain permission directly from the copyright holder. To view a copy of this licence, visit http:// creativecommons.org/licenses/by/4.0/.

\section{References}

Cheng, Yu, and Yunshi Huang (程瑜、黄韵诗). 2014. “The Shielded Gynecopathy: A Study on the Selection of Behavior of Seeing Doctor among Womxen of Dong People in a Village of Liuzhou City, Guangxi” (被遮蔽的妇科病:广西柳州侗寨妇女的就医选择). Ethno-national Studies (民族研究) 6: 69-75.

Das, Veena. 2012. Ordinary ethics. In A companion to moral anthropology, ed. Didier Fassin. MA: WileyBlackwell.

Ember, Carol R., and Melvin Ember. 2004. Encyclopedia of medical anthropology. New York: Kluwer Academic/Plenum Publishers.

Giddens, Anthony. 1990. The Consequences of Modernity. California: Stanford University Press.

Jing, Jun, and Pengcheng Huang (景军、黄鹏程). 2016. “Doctor-Patient Relation and its Effect on the Abuse of Antibiotics in Rural Areas: A Case Study of Five Rural Clinics” (医患关系对农村抗生素滥 用的作用: 以五个乡村诊所为例). The Journal of Minzu University of Guizhou (贵州民族大学学报. 哲 学社会科学版) 3: 45-52.

Kleinman, Arthur. 1980. Patients and healers in the context of culture. Berkeley: University of California Press.

Lambek, Michael. 2010. Ordinary ethics: Anthropology, language, and action. NY: Fordham University Press.

Latour, Bruno, and Steve Woolgar. 1986. Laboratory life: The construction of scientific facts. Princeton: Princeton University Press.

Leslie, Charlie. 1973. The professionalizing ideology of medical revivalism. In Entrepreneurship and modernization of occupational structures in South Asia, ed. M.B. Singer. Durham: Duke University Press. 
Leslie, Charlie. 1976. Asian medical systems: A comparative study. Berkeley: University of California Press.

Li, Yongxiang (李永祥). 2009. “The concept of disease and traditional therapy of YI people” (彝族的疾病 观念与传统疗法). Ethno-national Studies (民族研究) 4: 45-54.

Liu, Hongtao (刘宏涛). 2013. “A new explanation of healing rituals: The concept of disease of Meifu Li people in Hainan Province and their cultural logic in healing” (仪式治疗新解:海南美孚黎的疾病观念 和仪式治疗的文化逻辑). Ethno-national Studies (民族研究) 1: 58-66.

Liu, Zhiyang (刘志扬). 2006. “The cultural concept of Tibetan farmers in the choice of medical behavior”(西 藏农民在就医行为选择上的文化观念). The Open Times (开放时代) 4: 111-123.

Lock, Margaret, and Vinh-Kim Nguyen. 2010. An anthropology of biomedicine. Oxford: Wiley-Blackwell.

Roberts, Elizabeth F. 2012. God's laboratory: Assisted reproduction in the Andes. Berkeley: University of California Press.

Xu, Yiqiang (徐义强). 2012. “Medical anthropology discussion on Hani People's diverse medical systems and Behavioral health” (哈尼族多元医疗体系与行为健康的医学人类学讨论). Ethno-national Studies of Qinghai (青海民族研究) 3: 23-27.

Yan, Yunxiang (阎云翔). 2000. “The Flow of Gifts: Reciprocity and Social Networks in a Chinese Village" (礼物的流动:一个中国村庄中的互惠原则与社会网络), translated by Li Fangchun et al.(李放春等译). Shanghai: Shanghai People's Publishing House (上海人民出版社).

Yu, Chengpu (余成普). 2016. “The conceptual origin of local Biologies and their theoretical implications”(地方生物学:概念缘起与理论意涵). Ethno-national Studies (民族研究) 6: 102-115.

Zhang, Shi, and Yanji Zheng (张实、郑艳姬). 2015. “Integrity of Treatment: Rethinking Based on Medical Pluralism” (治疗的整体性:多元医疗的再思考). The Journal of Minzu University of China (中央民族 大学学报.哲学社会科学版) 4: 96-103.

Zhang, Xun (张珣). 2000. Disease and culture. Taipei: Daoxiang Publishing House (台北稻乡出版社).

Zhang, Youchun (张有春). 2011. "Anthropological Interpretation of the Process of Treatment in a Village" (一个乡村治病过程的人类学解读). The Journal of Minzu University of Guangxi (广西民族大学学 报·哲学社会科学版) 4: 57-61.

\section{Comments}

Publisher's Note Springer Nature remains neutral with regard to jurisdictional claims in published maps and institutional affiliations. 